\title{
Farmer's Profitability of Tobacco Cultivation at Rangpur District in the Socio-Economic Context of Bangladesh: An Empirical Analysis
}

\author{
Mohammad Masudul Hassan ${ }^{1}$, Mosammod Mahamuda Parvin ${ }^{2}$, Samira Islam Resmi ${ }^{1, \text { * }}$ \\ ${ }^{1}$ Faculty of Agribusiness Management, Sher-e-Bangla Agricultural University, Dhaka-1207, Bangladesh \\ ${ }^{2}$ Department of Management \& Finance, Sher-e-Bangla Agricultural University, Dhaka-1207, Bangladesh \\ Email address: \\ masudul@hotmail.com (M. M. Hassan), mahamudaparvin@gmail.com (M. M. Parvin), samira.islam@outlook.com (S. I. Resmi)
}

\section{To cite this article:}

Mohammad Masudul Hassan, Mosammod Mahamuda Parvin, Samira Islam Resmi. Farmer's Profitability of Tobacco Cultivation at Rangpur District in the Socio-Economic Context of Bangladesh: An Empirical Analysis. International Journal of Economics, Finance and Management Sciences. Vol. 3, No. 2, 2015, pp. 91-98. doi: 10.11648/j.ijefm.20150302.13

\begin{abstract}
Bangladesh is mainly an agricultural country. Agriculture is the major stay of the economy of Bangladesh. Agriculture is the crucial way of life of Bangladesh. Agriculture bears an anticipative contribution to the Gross Domestic Product (GDP) of the country prior to a greater extent than 50\% of GDP. At present greater portion of Bangladesh's GDP comes from the service sector. Notwithstanding this, two-thirds of the country's population is engrossed in agricultural practices. A variety of crops are cultivated in this country which categorized into two-food crops and cash crops. Tobacco is being dealt as leading cash crop in the world in addition to Bangladesh. This study was carried on to bringing close together the cost of production and profitability of Tobacco producers at Rangpur district. Data was gathered from 65 farmers using simple random sampling method. The Tobacco farmers demonstrated individual differences of opinion in their socio-economic characteristics and unconditional majority of them belonged to young age category (20-35 years)having medium family size, illiterate, medium farm size ( $0.34-1.0$ acre), ( 1 - 10 years) farming experience. The largest part of the Farmers used Virginia variety of Tobacco and sells their amount produced at home. Farmers who put up for sale Tobacco in the market were further profitable than others. The study further more denominates that the large farmers were almost profitable likened to others. Main difficulty confronted by the Tobacco farmers were lower price of Tobacco during harvesting period, price fluctuation , shortage of capital, lack of good quality seed, poor storage facility, higher price of inputs and lack of marketing facility etc. Appropriate measures should be necessitated by Government to figure out this problem. The findings of the study will add fundamental economic data on the production practices of Tobacco. Ultimately it will be supportive to the planners and policy makers in formulating micro or macro level policy for the improvement of Tobacco production in the country.
\end{abstract}

Keywords: Benefit Cost Ratio, Cash Crop, Production Function, Virginia, Marketing Cost

\section{Introduction}

Bangladesh is primarily an agricultural based country subjugated by crop production. Bangladesh enjoys by and large a sub-tropical monsoon climate. Bangladesh has been renowned for growing large variety of tropical crops particularly rice, wheat, Tobacco, jute, pulses, oilseeds, sugarcane etc.

Tobacco industry is a prospective industry and its escalation is also connected with national GDP. About one percent of our GDP is used in spending of tobacco product that is why it becomes a huge market for the challengers of tobacco industry.
Tobacco has been licked for at least the last three thousand years. Christopher Columbus discovered it when he landed in the Americas in 1492, but earliest holy place carvings demonstrate tobacco being smoked in Central America as long before as 1,000 BC. Ever from the time when it indoors in Europe in the late 15th century, tobacco has separated estimation, sparked disagreement and committed extensive revenue all the way through tax.

Tobacco has been brought in mid sixties of the preceding century into the fields where food crops were grown, and more extensively subsequent to liberation in 1971 by the British American Tobacco Company in Testa silt in Rangpur District area. Even though Bangladesh Agricultural Research 
Institute (BARI) has carried on research and improvement actions of tobacco and forsaken in 1995, tobacco production has essentially been pushed by big multinational companies such as British American Tobacco Company through contract growers. Bangladesh is one of the biggest tobacco overwhelming countries in the world. Tobacco farming is responsible for less than $0.5 \%$ of agricultural employment in Bangladesh.

The tobacco plant is over and over again termed as a weed since of its ability to germinate on any soil. In fact this crop has been considered to be mounting on soils where other crops have unsuccessful to fructify. In Bangladesh, tobacco is fundamentally a Rabi season crop with sowing being done during mid-October to mid-December. From the day the seeds are sown, it takes about 6-7 months to mature. It may be pointed out here that a number of Rabi season food and cash crops are also sown during this period implying that tobacco competes with these other food crops. There are about 60 different species of tobacco though the most popular ones are Nicotiana Tabacum and Nicotiana Rustica. In Bangladesh, various types of tobacco such as Dark Virginia Gold, Motihari, Jyoti, etc. are grown. Virginia is used primarily in the production of cigarettes while the nonVirginia types are used in producing Bidi and other products.

Tobacco has the status of being a very money-making crop with few 'evenly profitable' substitutes. Among the variety of argues mentioned by the farmers for cultivating tobacco, the profitability portion was devastating principal Eighty-five percent regarded this is an extremely beneficial crop.

\section{Review of Literature}

Assessment of related literatures in any research is necessary in the good judgment that it allows for an extent for reviewing the collection of knowledge \& information appropriate to the future research. This knowledge \& information give an instruction in designing the potential research problem $\&$ validating the new determinations.

It may be noted that profitability of tobacco cultivation is lucrative compared to some other crops. It ranks 15 among the major subsistence and cash crops in terms of financial profitability on the basis of full costs (see Zohir ).

Most of the tobacco farmers are deprived off such profitability by denying a fair price of their 10 products through unscrupulous activities of the middlemen, moneylenders, and hostile BAT officials (see Chowdhury

According to UBINIG research, there are several reasons including cash earning, perceived high profit, guarantee of inputs and market and also the involvement of farmers through company card plays a coercive role for continuing tobacco cultivation. (Farida Akhter).

According to the official Agricultural Statistics (2010), three varieties of tobacco -- Jati, Motihari and Virginia -- are grown in different districts of Bangladesh. Jati and Motihari are mostly grown in Rangpur and Bandarban district, while Virginia is mostly grown in Kushtia, Rangpur, Jessore and Dhaka District. Other varieties such as Burley are also grown in limited quantities. In terms of land area covered by all three kinds of tobacco, Rangpur district still remains highest with 40345 acres during 2008-09 followed by Kushtia district 22241 and Bandarban District 4678 acres of land. Besides tobacco is extending to Jessore, Jhenaidah, Nilphamari, Lalmonirhat and even in Manikganj and Tangail district.

The production of Virginia variety of tobacco during 20089 was 22,277 metric tons, while the other varieties, such as Jati were 8,437 metric tons and Motihari was 9,270 metric tons.

In the 2005-06 financial year, Bangladesh exported tobacco worth 95 crore 85 lakh 35 thousand (over 958 million) taka.

Bangladesh is one of the largest tobacco consuming countries in the world. Tobacco is grown throughout the country, with the largest tobacco growing areas including Rangpur, Kushtia, and Chittagong Hill. After many years as a net importer of tobacco leaf, acreage and yields rose beginning 1999, and Bangladesh has become a net exporter in recent years, exporting about one-third of the tobacco grown ( Barakat A. et al.).

Hassain (1998) studied tobacco marketing in the two most important tobacco growing areas of Rangpur and kushtia districts of Bangladesh. He showed that the production and processing cost per hectare of tobacco of Rangpur and kushtia district were TK. 2158 and TK. 31312 respectively. The net return per acre was TK. 2713 in Rangpur while it was TK. 5080 for kushtia district.

Mahmud (1999) conducted a socioeconomic study on tobacco production in some selected areas of Rangpur district where he showed that tobacco growing was a profitable business, but the Virginia variety was more profitable than the Matihari. The total costs of tobacco production per hectare were Tk. 34260 and Tk. 35106 for Virgina and Matihari varieties respectively. The net returns of tobacco production were Tk. 9690 and Tk. 5914 per hectare in the study area.

\section{Objectives}

1. To delineate the socio-economic characteristics of Tobacco producers in the study area through farm size.

2. To delimitate the profitability of Tobacco production across farm size.

3. To ascertain the problems of Tobacco cultivation across farm size.

4. To put forward policy implications for improvement of Tobacco production in Bangladesh.

\section{Statement of the Problem}

Agriculture is the salvation of Bangladesh. The most important livelihood of the people of Bangladesh is associated with Agriculture. Farmers of this country at the outset produce crops what satisfies family life wants then they exemplify interest on production of cash crop such as 
cotton, jute, tea, tobacco, coffee, and so on are mostly expected in dealing demand of home market and sell abroad in foreign currency in support of developing countries.

Tobacco has a substantial implication in nationalized economy. Small hard work has been completed to study the economics of the tobacco production. By the way cost of production and profitability determination should be premeditated. This study will be intended at determining causes of variation and aspect of success among farms growing tobacco; it is indispensable both for the farmers and planners to carry out a programme considered for eliciting agricultural production. Updating knowledge on profitability of Tobacco is one rationalization of this study. It is essential to evaluate substitute profitability of this investment in terms of land and other resources keen to tobacco farming.

This research possibly will endow with a number of detailed benefits to the individual farmers for efficient operation and management of the farm and also to the research personnel for supplementary studies of related natural history and to the planners and policy makers who provide the farmers centrally for Marco- level strategy assessment.

\section{Methodology of the Study}

The survey method is probably the most widely used formal method obtaining farm management data. This chapter discusses about the selection of the study area, period of the study, sampling technique and sample size, data processing and analysis.

\subsection{Selection of the Area}

Rangpur district was chosen purposively as a study area because this district is one of the renowned for Tobacco production in Bangladesh. Gangachara Sub-district was selected at random from the 7 Sub-district of Rangpur districts as the study area. An opening survey was carried on in some villages of Gangachara Sub-district to collect primary knowledge about the Tobacco production, productivity and efficiency of the Tobacco growers. After preliminary visit three village's namely Utttor Panapukur, Dhakshin Panapukur and Betgari were selected randomly as the study area. Most of the farmers in these villages used to produce high yielding varieties of Tobacco and sell their product to different middlemen. The main criteria behind the selection of the Sub-district were as follows:

[1] The selected Sub-district was a good Tobacco producing area.

[2] The researcher is well-known with the language, living, beliefs, and other socio-economic characteristics of the villages of this Sub-district.

[3] Previously such type of study was not conducted in this area.

\subsection{Period of the Study}

Data for the study were collected from winter and summer season of 2013-2014.

\subsection{Selection of the Sample and Sampling Techniques}

A random sampling technique was applied for selecting sample. Through random sampling 65 farmers were selected for the study. Among the 65 farmers, 22 were small, 28 were medium and 15 were large. Farm size was arbitrarily classified on the basis of their land where they produce Tobacco and other crops. Farmers having 0.01-0.33 acre considered as small, 0.34-1.00 acre as medium farmers while those having above 1.00 acre as large farmers.

\subsection{Sources of Data}

The study is involved in collection of data both from the primary and secondary sources. Different types of data and their sources are discussed under the following heads:

\subsubsection{Primary Data}

Primary data were collected by the researcher themselves through personal interview with the respondents. To get accuracy and reliability of data, care and caution were taken in data collection. The researcher's took all possible effort to establish a congenial relationship with the respondents do not feel hesitation or hostile to provide correct data. Prior to interviewing, the objectives of the study were explained to each and every owner of the Tobacco growers. As a result, they were convinced that the study was purely an academic one and was not likely to have an adverse effect on their business. During data collection an attention was also paid to the mood of the owners of the Tobacco growers.

\subsubsection{Secondary Data}

We can't get enough secondary data for this study. The secondary sources include govt. publications; annual reports on Tobacco cultivation, seminar papers, journals, published and unpublished thesis, and topic reelected various books, BBS, web site etc.

\subsection{Processing and Analysis of Data}

Collected data were scrutinized and summarized for the purpose of tabulation using the Statistical Package for Social Sciences (SPSS) and Microsoft office Excel 2013. Two techniques of analysis were used in this study, tabular and statistical. Analysis by tabular technique included socioeconomic characteristics of Tobacco farmers, classification of size of Tobacco land, production practices, inputs used and returns of Tobacco farmers. Statistical analysis was used to show the effect of inputs used and other related factors of Tobacco cultivation.

\subsection{Empirical Model}

In this study, we assume that the Cobb-Douglas is the appropriate form of the frontier production function. The stochastic production function which is used for the Tobacco producers was specified as:

$$
\mathrm{LnY}_{\mathrm{i}}=\beta_{0}+\beta_{1} \ln \left(\mathrm{X}_{1}\right)+\beta_{2} \ln \left(\mathrm{X}_{2}\right)+\beta_{3} \ln \left(\mathrm{X}_{3}\right)+\beta_{4} \ln \left(\mathrm{X}_{4}\right)+\beta_{5}
$$




$$
\begin{gathered}
\ln \left(X_{5}\right)+\beta_{6} \ln \left(X_{6}\right)+\beta_{7} \ln \left(X_{7}\right)+\beta_{8} \ln \left(X_{8}\right)+\beta_{9} \ln \left(X_{9}\right)+\ln \left(X_{10}\right) \\
+\ln \left(X_{11}\right)+\ln \left(X_{12}\right)
\end{gathered}
$$

Where,

ln= Natural logarithm

$\mathrm{Y}=$ Total Tobacco Production

$\beta_{0}=$ Constant or intercept value

$\mathrm{X}_{1}=$ land value cost

$\mathrm{X}_{2}=$ land preparation Cost

$\mathrm{X}_{3}=$ Seed \& planting Cost

$\mathrm{X}_{4}=$ Cow dung Cost

$\mathrm{X}_{5}=$ Fertilizer $($ Urea/TSP/MP) Cost

$\mathrm{X}_{6}=$ Labor Cost

$\mathrm{X}_{7}=$ Insecticides/Pesticides Cost

$\mathrm{X}_{8}=$ Irrigation Cost

$\mathrm{X}_{9}=$ Harvesting Cost

$\mathrm{X}_{10}=$ Drying \& Processing Cost

$\mathrm{X}_{11}=$ Marketing Cost

$\mathrm{X}_{12}=$ Others Cost

\section{Results and Discussion}

\section{Socio-Economic Characteristics of Tobacco Farmers}

The socio-economic background and characteristics of the farmer's influences the productions to a great extent. So, a description of the characteristics of farmer is necessary for analyzing the main objective of the present study. Socioeconomic characteristics of the farmer's included their age, family size, educational status, farm size, farming experience, use of seed variety, and place of sale of the respondent. These are described below:

\begin{tabular}{|c|c|c|c|c|}
\hline \multirow{2}{*}{ Age categories } & \multicolumn{2}{|c|}{ Tobacco farmers } & \multirow{2}{*}{ Mean } & \multirow{2}{*}{ SD } \\
\hline & Number & $\%$ & & \\
\hline Young (20-35years ) & 29 & 44.6 & \multirow{4}{*}{1.77} & \multirow{4}{*}{.786} \\
\hline Middle (35-50 years) & 22 & 33.3 & & \\
\hline old ( Above50years ) & 14 & 21.5 & & \\
\hline Total & 65 & 100 & & \\
\hline
\end{tabular}

Table 1. Distribution of the Tobacco farmers according to their age.

Source: Field survey.

Table 1: demonstrates that age of the Tobacco farmers ranged from 20 to above 50 years, with the mean of 1.77 years and the standard deviation 0.786. Tobacco farmers were classified into three categories on the basis of their age. Young farmers are mostly engaged in Tobacco cultivation.

Table 2. Distribution of the Tobacco farmers according to their education.

\begin{tabular}{lllll}
\hline \multirow{2}{*}{ Education categories } & \multicolumn{2}{l}{ Tobacco farmers } & \multirow{2}{*}{ Mean } & \multirow{2}{*}{ SD } \\
\cline { 2 - 3 } & Number & $\mathbf{\%}$ & & \\
\hline Illiterate & 32 & 49.2 & & \\
Primary & 18 & 27.7 & & \\
secondary & 8 & 12.3 & 1.85 & 1.019 \\
Higher secondary & 7 & 10.8 & & \\
Total & 65 & 100 & & \\
\hline
\end{tabular}

Source: Field survey.
Table 2: depicts that maximum farmers $(49.2 \%)$ are illiterate while primary (27.7) and secondary have $(12.3 \%)$.Farmers having higher secondary education are (10.8\%). Tobacco farmers were classified into four categories on the basis of their education along with the mean of 1.85 and the standard deviation 1.019. Illiterate farmers are generally pursued in Tobacco cultivation.

\begin{tabular}{|c|c|c|c|c|}
\hline \multirow{2}{*}{ Family size } & \multicolumn{2}{|c|}{ Tobacco farmers } & \multirow{2}{*}{ Mean } & \multirow{2}{*}{ SD } \\
\hline & Number & $\%$ & & \\
\hline Small (1-4) & 22 & 33.8 & \multirow{4}{*}{1.88} & \multirow{4}{*}{.740} \\
\hline Medium ( 5-6) & 29 & 44.6 & & \\
\hline Large ( above7) & 14 & 21.5 & & \\
\hline Total & 65 & 100 & & \\
\hline
\end{tabular}

Table 3. Distribution of the Tobacco farmers according to their Family size.

Source: Field survey.

In Table 3: Family size of the Tobacco farmers of the study ranged from 1 to above 7 persons, with an average of 1.88 persons and standard deviation 0.740 . Tobacco farmers were classified into three categories because of their family size.

Tobacco farmers inducing medium family size (44.6\%) are interest group in Tobacco cultivation.

\begin{tabular}{|c|c|c|c|c|}
\hline \multirow{2}{*}{ Family size } & \multicolumn{2}{|c|}{ Tobacco farmers } & \multirow{2}{*}{ Mean } & \multirow{2}{*}{ SD } \\
\hline & Number & $\%$ & & \\
\hline Small(0.01-0.33 acre) & 22 & 33.8 & \multirow{4}{*}{1.89} & \multirow{4}{*}{.753} \\
\hline Medium(0.34-1.0 acre) & 28 & 43.1 & & \\
\hline Large ( above7 acre) & 15 & 23.1 & & \\
\hline Total & 65 & 100 & & \\
\hline
\end{tabular}

Table 4. Distribution of the Tobacco farmers according to their Farm size.

Source: Field survey.

Table 4: describes that Tobacco farmers were classified into three categories due to their farm size. Maximum Tobacco farmers are belonging to medium farm (43.1\%) with the mean of 1.89 acre and the standard deviation 0.753 .

Table 5.Distribution of the Tobacco farmers according to their Farming experience.

\begin{tabular}{lllll}
\hline \multirow{2}{*}{ Faming Experience } & \multicolumn{2}{l}{ Tobacco farmers } & \multirow{2}{*}{ Mean } & SD \\
\cline { 2 - 3 } & Number & $\mathbf{\%}$ & & \\
\hline Above20years & 29 & 44.6 & & \\
10-20years & 25 & 38.5 & 1.72 & .740 \\
1-10years & 11 & 16.9 & & \\
Total & 65 & 100 & & \\
\hline
\end{tabular}

Source: Field survey.

In Table 5:Farming experience of a respondent was determined by reason of involvement in the farming activities related to agriculture. Tobacco farmers placed from 1 to above 20 years, with the mean of 1.72 years and the standard deviation .740. Tobacco farmers were sorted into three categories on the basis of their Farming experience.

Uppermost portion of the Tobacco farmers (44.6\%) had low farming experience (Above 20 years). 
Table 6. Distribution of the Tobacco farmers according to the use of Seed variety.

\begin{tabular}{lllll}
\hline \multirow{2}{*}{ Seed variety } & \multicolumn{2}{l}{ Tobacco farmers } & \multirow{2}{*}{ Mean } & \multirow{2}{*}{ SD } \\
\cline { 2 - 3 } & Number & $\%$ & & \\
\hline Virginia & 47 & 72.3 & 1.28 & .451 \\
Jati & 18 & 27.7 & & \\
Total & 65 & 100 & & \\
\hline
\end{tabular}

Source: Field survey.

From Table 6: it is shown that Tobacco farmers were classified into two categories on account of their use of seed variety. The majority of the farmers make use of Virginia seed of Tobacco $(72.3 \%)$. Farmer use Jati variety relatively low
$(27.7 \%)$.

Table 7. Distribution of the Tobacco farmers according to the place of sale.

\begin{tabular}{lllll}
\hline \multirow{2}{*}{ Place of sale } & \multicolumn{2}{l}{ Tobacco farmers } & \multirow{2}{*}{ Mean } & \multirow{2}{*}{ SD } \\
\cline { 2 - 3 } & Number & \% & & \\
\hline Home & 42 & 64.6 & 1.35 & .482 \\
Market & 23 & 35.4 & & \\
Total & 65 & 100 & & \\
\hline
\end{tabular}

Source: Field survey.

Table 7: exhibits that nearly all of the Tobacco farmers sold Tobacco at home $(64.6 \%)$.selling percentage in market is consistently poor $(35.4 \%)$.

Table 8. Distribution of the type of farmers according to the place of sale.

\begin{tabular}{llll}
\hline \multirow{2}{*}{ Place of sale } & Type of Farmer & & Targe( above 1.0 acre) \\
\cline { 2 - 4 } & Small(0.01-0.33acre) & Medium(0.34-1.0 acre) & Total \\
\hline Home & 14 & 26 & 2 \\
Market & 8 & 2 & 13 \\
Total & 22 & 28 & 15 \\
\hline
\end{tabular}

Source: Field survey.

Table 8: Indicates that most of the Medium Farmers sell their

Tobacco at Home. But Maximum Large Farmers sell at

Market. Small farmer sell together Home and Market.

Table 9. Per acre cost of Tobacco cultivation in the study areas.

\begin{tabular}{|c|c|c|c|c|}
\hline Cost Head & Small Farmer & Medium Farmer & Large Farmer & Total \\
\hline land preparation & 18870 & 58830 & 68700 & 146400 \\
\hline Seed \& planting Cost & 44030 & 137270 & 160300 & 341600 \\
\hline Cow dung Cost & 12010 & 39070 & 44900 & 95980 \\
\hline Fertilizer(Urea/TSP/MP) & 60635.6 & 189040.4 & 220756 & 470432 \\
\hline Labour Cost & 81770 & 254930 & 297700 & 634400 \\
\hline Insecticides/Pesticides & 5032 & 15688 & 18320 & 39040 \\
\hline Harvesting & 31450 & 98050 & 114500 & 244000 \\
\hline Drying \& Processing & 12380 & 38990 & 45070 & 96440 \\
\hline Marketing & 1250 & 600 & 2680 & 4530 \\
\hline Others & 8806 & 27454 & 32060 & 68320 \\
\hline Total variable cost & 288333.6 & 898922.4 & 1049736 & 2236992 \\
\hline Land value & 75480 & 235320 & 274800 & 585600 \\
\hline Total fixed cost & 75480 & 235320 & 274800 & 585600 \\
\hline Total cost $=($ Variable + Fixed $)$ cost & 363813.6 & 1134242 & 1324536 & 2822592 \\
\hline
\end{tabular}

Source: Field survey.

*The above table is Figured in Units BDT TAKA (Currency of Bangladesh with 1USD = 78.02 BDT)

In the table 9: Per acre Cost of Tobacco cultivation of Small, Medium and large farmers are exposed. Total variable cost include Total cost was the summation of total variable cost and total fixed cost. Total cost was highest for large farmers (TK. 1324536.) followed by medium farmers (TK.1134342) and small farmers (TK.363813.6).

Table 10. Per acre Profitability and Benefit Cost Ratio of Tobacco cultivation in the study areas.

\begin{tabular}{|c|c|c|c|c|}
\hline Item & Small Farmer & Medium Farmer & Large Farmer & Total \\
\hline Total land use ( acre) & 6.29 & 19.61 & 22.9 & 48.8 \\
\hline Tobacco Output (mon) & 150.96 & 470.64 & 549.6 & 1171.2 \\
\hline Tobacco TK per $40 \mathrm{~kg}$ & 3010 & 3000 & 3020 & 9030 \\
\hline Tobacco By Product TK per $40 \mathrm{~kg}$ & 210 & 220 & 225 & 655 \\
\hline Total revenue & $\begin{array}{l}(150.96 * 3010)+(75.48 * 210) \\
=469485.6\end{array}$ & $\begin{array}{l}(470.64 * 3000)+(235.32 * 220)= \\
1463690\end{array}$ & $\begin{array}{l}(549.6 * 3020)+(274.8 * 225) \\
=1721622\end{array}$ & 3654798 \\
\hline Total cost & 363813.6 & 1134242 & 1324536 & 2822592 \\
\hline Net profit & 105672 & 329448 & 397086 & 832206 \\
\hline Benefit Cost Ratio $=\frac{\text { Total Revenue }}{\text { Total Cost }}$ & 1.29 & & & \\
\hline
\end{tabular}

Source: Field survey

*The above Table is Figured in mon $(1 \mathrm{mon}=40 \mathrm{~kg})$ 
Table10: points out that Productivity is highest for large farmer $(549.6+274.8=824.4$ mon $)$ followed by Medium farmer $(470.64+235.32=705.96$ mon $)$ and small farmer $(150.96+75.48=226.44$ mon $)$. Profitability is also highest for large Farmers (TK. 397086) followed by medium farmer (TK.
329448) and small Farmer (TK. 105672). Because most of the large farmer has more land as well as more output and they also sell their Tobacco in the market but Medium and small farmer sell at home (Table 8 and Table 10).

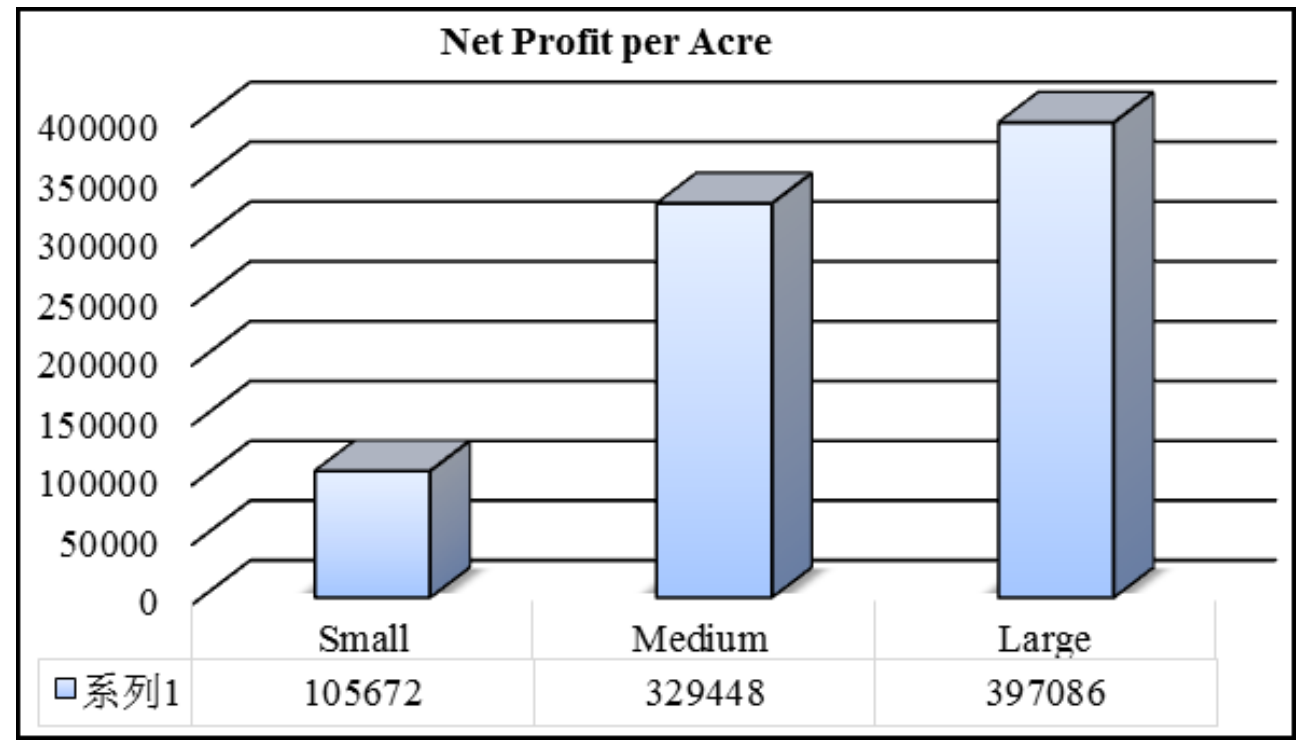

Figure 1.Per acre net profit of Tobacco cultivation in the study areas.

Source: Field survey.

Table 11. Correlations.

\begin{tabular}{|c|c|c|c|c|c|c|c|c|c|}
\hline & Land value & Seed & Fertilizer & Insecticides & Irrigation & Labor & Harvesting & total cost & total revenue \\
\hline Land value & 1 & & & & & & & & \\
\hline Seed & $.729(* *)$ & 1 & & & & & & & \\
\hline Fertilizer & $.778(* *)$ & $.882(* *)$ & 1 & & & & & & \\
\hline Insecticides & $.539(* *)$ & $.766(* *)$ & $.570(* *)$ & 1 & & & & & \\
\hline Irrigation & $.901(* *)$ & $.472(* *)$ & $.626(* *)$ & .123 & 1 & & & & \\
\hline Labour & $.957(* *)$ & $.815(* *)$ & $.794(* *)$ & $.750(* *)$ & $.743(* *)$ & 1 & & & \\
\hline Harvesting & $.946(* *)$ & $.745(* *)$ & $.744(* *)$ & $.559(* *)$ & $.829(* *)$ & $.937(* *)$ & 1 & & \\
\hline total cost & $.953(* *)$ & $.829(* *)$ & $.788(* *)$ & $.759(* *)$ & $.735(* *)$ & $.996(* *)$ & $.940(* *)$ & 1 & \\
\hline total revenue & $.942(* *)$ & $.841(* *)$ & $.790(* *)$ & $.779(* *)$ & $.710(* *)$ & $.994(* *)$ & $.938(* *)$ & $.998(* *)$ & 1 \\
\hline
\end{tabular}

Source: Field survey

** Correlation is significant at the 0.01 level (2-tailed).

* Correlation is significant at the 0.05 level (2-tailed).

1. There is a significant positive correlation between Total cost and Labor cost .Because when Farmers uses more labor for better output, then Total cost increases.

2. There is significant positive correlation between land value and harvesting cost. Because higher land value means more fertile of land that provides more output. As a result harvesting cost increases.

3. There is significant positive correlation between Fertilizer cost and Seed cost. Since the Farmers use better seed for more output desire amount of output, therefore they provide better Fertilizer. As a result, Fertilizer cost increase.

4. There is significant positive correlation between
Irrigation and Land value. Since the land value increases, Farmers wants to maximize profit by getting best output providing sufficient Irrigation. Consequently Irrigation cost increase.

5. There is significant positive correlation between Insecticides cost and Seed cost. As insecticides keep the seed disease free, so Insecticides cost increases when seed cost increases.

6. There is significant positive correlation between seed cost and Land value. Since the Land value increase, Farmers want to produce more output desire amount of output, therefore they provide better seed. As a result, Seed cost increase. 
7. There is a significant positive correlation between Total increases, then Farmers Net revenue also increases. revenue and Total cost. When Farmers Total cost

Table 12. Factors affecting profitability of Tobacco production.

\begin{tabular}{|c|c|c|c|c|}
\hline \multirow{2}{*}{ Variable } & \multicolumn{2}{|c|}{ Coefficients } & \multirow{2}{*}{ T-Value } & \multirow{2}{*}{ Sig. } \\
\hline & B & S.E & & \\
\hline Constants & .436 & 12151 & .035 & .961 \\
\hline Natural logarithm land value cost & .442 & .371 & 1.163 & .258 \\
\hline Natural logarithm land preparation Cost & -.296 & .711 & -.412 & .765 \\
\hline Natural logarithm Seed \& planting Cost & -2.741 & .633 & -4.322 & .000 \\
\hline Natural logarithm Cow dung Cost & -.736 & .355 & -2.033 & .046 \\
\hline Natural logarithm Fertilizer (Urea/TSP/MP) Cost & -3.002 & .301 & -9.912 & .000 \\
\hline Natural logarithm Labour Cost & 1.157 & .371 & 3.103 & .003 \\
\hline Natural logarithm Insecticides/Pesticides Cost & -.507 & .318 & -1.391 & .209 \\
\hline Natural logarithm Irrigation Cost & 5.890 & .603 & 11.511 & .000 \\
\hline Natural logarithm Harvesting Cost & -1.467 & 1.194 & -1.136 & .276 \\
\hline Natural logarithm Drying \& Processing Cost & .341 & .303 & 1.101 & .211 \\
\hline Natural logarithm Marketing Cost & .411 & .321 & 1.121 & .279 \\
\hline Natural logarithm Others Cost & -.603 & .392 & -1.281 & .243 \\
\hline
\end{tabular}

Source: Field survey

Table 12: implies that factors affecting the yield and profitability of Cobb-Douglas production function of Tobacco. The results of the production function depicts that among the selected variables, four variables namely, Seed \& planting Cost, Fertilizer (Urea/TSP/MP) Cost, Labor Cost and Irrigation Cost, arc significant at $1 \%$ level and Cow dung Cost is significant at $5 \%$ level of significance while the other variables: land value cost, land preparation cost, Insecticides/Pesticides cost, Harvesting cost, Drying \& Processing cost, Marketing cost, Others cost are not significant.

As for case in point, the coefficient of labor cost per Acre is 1.157 means that if the other things remain constant, production of Tobacco will be increased by $1.157 \%$ for $1 \%$ increase in labor cost. In the same way Irrigation Cost also affected the production of Tobacco positively. The coefficient of Seed \& planting Cost per Acre is 2.741 means that if the other things remain constant, Tobacco production will be reduced by- $2.741 \%$ for $1 \%$ increasing in the use of seed. By the same token, Fertilizer (Urea/TSP/MP) Cost and Cow dung Cost also affected the production of Tobacco negatively. Conversely, insignificant character of land value cost, land preparation cost, Insecticides/Pesticides cost, Harvesting cost, Drying \& Processing cost, Marketing cost, Others cost had no significant effect on the total Tobacco production.

\section{Problems}

1. Low prices at peak harvest period

2. High cost of inputs

3. Lack of adequate funds

4. Unavailability of quality fertilizers in time

5. Disease infestation in winter.

6. Labor crisis

7. Unavailability of good quality seed

8. Lack of Government attention.

9. Syndicate of businessmen

10. Need for immediate sale
11. Delay in payment by traders

12. Farmers did not get proper price due to improper marketing channel/system

13. Lack of farmers' knowledge on good quality seed and access to the seed.

14. Lack of linkage between farmers and exporter

15. Lack of coordination among research organizations like BARI, DAE and farmers and Agro/Tobacco processing companies.

16. Health and illness is honestly being affected among tobacco-cultivators through escalating smoking and leaf chewing practices in addition to through cultivation and drying of tobacco leafs.

\section{Recommendations}

Some recommendations are given below:

1. Virginia variety of Tobacco was more efficient than other variety. So, farmers may be encouraged to use this variety.

2. The price of Tobacco should be readjusted from time to time safeguarding justice to the growers of Tobacco.

3. Government should reduce the pesticide and insecticide price.

4. The consciousness of the farmers needs to be increased. They may be delivered adequate training so that they can produce Tobacco appropriately.

5. Modern technology should be taking on for superior labor cost control.

6. Agricultural credit facilities to be ensured easily.

7. Provision for the introduction of crop insurance should be introduced. Therefore, the risk of Tobacco cultivation would be minimized and farmers will get more ensured environment to produced Tobacco.

8. While tobacco cultivation is experiencing negative effect on health, management cost of tobacco farming and tobacco utilize should be compensated by the companies, and it ought to be fixed for the period of 
congregation with government for setting up purchasing cost of tobacco.

\section{Limitation of the Study}

[1] The study was restricted to one Sub-district where Tobacco production was intense. se3Three villages under that Sub-district were selected purposively. The study might be momentous outcome if it enclosed a number of Sub-district producing Tobaccos.

[2] Due to deficiency of time the study could not cover wide side areas for gathering obligatory information.

[3] Some written records were asserted by the literate respondents, but maximum respondents had no written document. Therefore, the researcher had to depend solely on the memory of the respondents.

[4] Respondents were very busy. A study that brings in interview of 65 farmers cannot conclude anything accurately and as such, it was based on miss information.

[5] The largest part of the farmers in the study area contemplation that the investigator was a government officer. So, they originally hesitated to answer the questions relating to their income and expenditure. Some were afraid of imposition of new taxes.

\section{Conclusions}

The main reason behind cultivating tobacco is the far and wide detained observation that tobacco is an especially lucrative crop. The situation of tobacco production \& its industry is extremely to a great extent competitive. Nevertheless this is a contentious crop production as to produces product with health exposure but the profits it begets and tax it adds in the national economy is an immense contribution.

The findings of the study that net profit per acre (TK.17053).This research shows medium farmers cultivate more land but net profit is highest for large farmers because large farmer sell tobacco in the market rather than home. Therefore, it can be said that net profit largely depends on marketing. Farmers get higher price at market than selling Tobacco at Home. Transportation facilities should be improved to facilitate the marketing process. Priority should be given to the development of such roads which link villages to the main roads and markets. Most of the farmers are illiterate. Dissemination of market information should be increased so that farmers can get fair price of the Tobacco.

Government or no additional agency can the tobacco farmer can put down his hands on durable ready cash the instant his produce is inclined of nothing like a good number other crops which yield proceeds as and when the Production is prepared for sale. This pretends as a most important unifying force for the farmers.

\section{References}

[1] Barkat A, Chowdhury AU, Nargis N, Rahman M, Kumar PkA, Bashir S, Chaloupka FJ., "The Economics of Tobacco and Tobacco Taxation in Bangladesh," Paris: International Union against Tuberculosis and Lung Disease, 2012.

[2] Chowdhury, M. A. M., “A Socioeconomic Analysis of Tobacco Cultivation in Bangladesh: A Case Study of Meherpur, Rangpur and Rangunia," Journal of Business Studies, Vol. 1, 2001, pp. 48-65.

[3] Hossain, M. M. (1998): A Study on Tobacco Marketing in Bangladesh. Unpublished M.S. Thesis, Department of Cooperation and Marketing, Bangladesh Agricultural University. Mymensingh.

[4] Hossain M. Agriculture in Bangladesh. Dhaka: University Press Limited, 1991. 464p.

[5] Mahmud, S. (1999): A social Economic Study on Tobacco Production in Some Selected Ares of Rangpur District. An Unpublished M.S Thesis Faculty of Agricultural Economics and Rural Sociology, Bangladesh Agricultural University, Mymensingh.

[6] Tobacco Cultivation and its Impact on Food Production in Bangladesh, Farida Akhter, UBINIG, 2008 (Bangladesh).Retrieved From http://www.fairtradetobacco.org/?page_id=199

[7] Yearbook of Agricultural Statistics of Bangladesh, 2009, Bangladesh Bureau of Statistics, Ministry of Planning, GOB, August 2010

[8] Zohir, S., "Impact of Reforms in Agricultural Input Markets on Crop Sector Profitability in Bangladesh, mimeo" Bangladesh Institute of Development Studies, Dhaka, .2001 